\title{
Experiences of rejection by mental health patients- A qualitative study
}

\author{
Bertil Lundberg ${ }^{1}$, Pia Lundqvist ${ }^{2}$, Lars Hansson $^{2}$, Elisabet Wentz ${ }^{3}$, Bengt Sivberg $^{2^{*}}$ \\ ${ }^{1}$ Department of Health Sciences, Faculty of Medicine, The Swedish Institute for Health Sciences, Lund University, Lund, Sweden \\ ${ }^{2}$ Department of Health Sciences, Faculty of Medicine, Lund University, Lund, Sweden; \\ *Corresponding Author: Bengt.Sivberg@med.lu.se \\ ${ }^{3}$ Gillberg Neuropsychiatry Centre, University of Gothenburg, Gothenburg, Sweden
}

Received 18 April 2013; revised 18 May 2013; accepted 20 June 2013

Copyright (C) 2013 Bertil Lundberg et al. This is an open access article distributed under the Creative Commons Attribution License, which permits unrestricted use, distribution, and reproduction in any medium, provided the original work is properly cited.

\section{ABSTRACT}

Background and aim: People suffering from mental illness and their experiences of attitudes towards them are rarely investigated from the perspective of the individual. The aim was to gain an understanding of how a group of mental health patients experienced social relationships in personal settings as well as in society. Method: Open interviews with twenty-five mental health patients were conducted and analysed with a qualitative content analysis. Result: The essence of the result was that mental health patients' experiences are still not taken enough into account, neither by mental health professionals nor by their social networks. This was underpinned by four core categories: Patients' experience of deteriorated and reduced social contacts due to various degrees of acceptance and knowledge of people in general; service users reported on difficulties with social contacts in general, with family relationships, relationships with friends and workmates and with employers; reduced life opportunities were expressed, including violated self-image and poor coping competence and, ambivalent experiences of contact with the mental health services were reported. Conclusion and clinical implication: The present study contributes to the understanding of mental health patients' experiences of professional services and of their social networks. This knowledge may strengthen the implications of patient-centred care essential for the outcome of the care.

Keywords: Mental Health Patients; Experiences; Stigma; Attitudes; Qualitative Interviews; Society;
Family

\section{INTRODUCTION}

People with serious mental illness no longer spend years of their lives in psychiatric institutions. In Sweden, as in many other countries, there has been a transition of care from hospitals into the community. However, this does not guarantee an acceptable inclusion in society. The barriers originate from the disability itself, the stigmatizing and discriminatory attitudes, and behaviours of the public as well as from the staff [1-3].

Stigma affects the identity of those barriers. The negative attribute is ascribed to, and complicates interactional encounters with those "the normals" called by Goffman [4]. To explain how the stigmatization as well as discrimination process develops, Link and Phelan [5] have described four stages: labelling, negative stereotyping, separation ("us" from "them") and, finally loss of status and discrimination. Political, economic and social powers contribute to shaping the prejudice and discrimination experienced by the mentally ill. These factors can explain the different ways in which the mentally ill patients are subject to disapproval and discrimination [5]. While there is considerable knowledge about attitudes and values in the general population towards people with mental illness, the research focusing on mental health patients' experiences is sparse.

Qualitative studies have been suggested to gain a deeper understanding of subjective experience of stigma [6-10] as well as a complement to quantitative studies. Studies investigating first-hand experience have revealed that stigma occurs in different dimensions, such as interpersonal interactions, structural discrimination, public perceptions of mental illness, access to social roles, quality of mental health services, and the internalization of 
stigma $[7,9,11]$. Therefore, it is important to study patients' experiences based on interviews to get an extended knowledge applicable for psychiatric nurses in their encounter with this group of patients. The aim was to gain an understanding of how a group of mental health patients, with reported high rates of rejection, experienced social relationships in personal settings as well as in society.

\section{METHODOLOGY}

\subsection{Participants}

The sample size was set to 25 informants, consecutively selected as follows. Informants from a cross-sectional study [12] were first asked to participate. Of the selected 25 informants, two declined to participate and four were not able to be contacted. The sample was then extended to 31 informants, to provide the final sample of 25 . Since the focus was on stigma experience the informants with the highest level of experience were asked to participate. Sociodemographic and clinical characteristics are presented in Table 1. The informants were contacted by a posted letter with information and after a few days they were contacted by telephone and asked for further participation in the present study. They were given the opportunity to put questions to the first author.

After receiving written consent, the informants were contacted by telephone for an interview appointment. The majority of the interviews took place in the informants' homes; three interviews were carried out within the premises of the user organizations or at the first author's office. The interview environment was selected in order to be as accommodating and calm as possible, so as to facilitate the informants' feelings of wellbeing. The time-span of the interviews varied between 45 to 90 minutes.

\subsection{Preunderstanding}

Qualitative content analysis is always to some extent depending on the preunderstanding of the interpreters in their analysis of the transcripts of the interviews. One way to stabilize a reasonable and reliable interpretation of a text is to have a systematic method to deal with the interpretations and at the same time to be aware of the influence of the different preunderstandings at hand. The text analysis was a teamwork mainly performed by the two first and the last authors but the results were discussed between all authors to reach a consensus. Their experiences included work as a psychiatric nurse, experience on clinical work with people with severe mental illness as well as earlier research on these groups of patients. Finally, two of the authors have extended experiences of qualitative content analysis.
Table 1. Sociodemographic and clinical characteristics $(n=$ 25).

\begin{tabular}{|c|c|}
\hline Gender & \\
\hline Male & 12 \\
\hline Female & 13 \\
\hline \multicolumn{2}{|l|}{ Age } \\
\hline $23-29$ & 6 \\
\hline $30-39$ & 3 \\
\hline $40-49$ & 5 \\
\hline $50-59$ & 6 \\
\hline $60-65$ & 5 \\
\hline Average age & 44 \\
\hline \multicolumn{2}{|l|}{ Domestic status } \\
\hline Alone & 14 \\
\hline Partner & 9 \\
\hline Parents & 2 \\
\hline \multicolumn{2}{|l|}{ Education } \\
\hline Primary School & 10 \\
\hline Upper secondary school & 10 \\
\hline Post secondary school & 5 \\
\hline \multicolumn{2}{|l|}{ Diagnosis } \\
\hline Psychosis & 15 \\
\hline Mood disorders & 7 \\
\hline Disorders of adult personality and behaviour & 3 \\
\hline \multicolumn{2}{|l|}{ Employment } \\
\hline Open labour market & 3 \\
\hline Sheltered/supported employment & 3 \\
\hline Unemployed & 2 \\
\hline Student & 2 \\
\hline Disability pension & 15 \\
\hline
\end{tabular}

\subsection{Data Collection}

An interview guide containing a few open-ended questions was used to encourage informants to talk as spontaneously as possible about their experiences. The opening question was: "Would you to tell me about your experiences as a mental health patient?" Follow-up questions were used in order to prompt the informant's narration. The interviews were tape-recorded and later transcribed verbatim by the first author.

\subsection{Analysis}

Content analysis was inspired by the methodology of Burnard [13,14], a method for systematic classification of data into categories. Each interview was read by two of the authors to obtain a sense of the whole of the interviews. In the process of analysis of the interviews units of meaning in the transcripts were identified and gath- 
ered into codes $(n=112)$ covering the content of the total transcribed text, excluding passages unrelated to the focus. This was carried out by two of the authors (BL and BS) separately. A preliminary list of codes was established by the first (BL), second (PL) and last author (BS). The analysis proceeded with a holistic reading of the transcripts in relation to the result of the coding and discussed under the tentative grouping of codes in higher order of preliminary categories. The authors made preliminary interpretations of the meaning of the text to gain understanding expressed in categories underpinned by the content covered by the codes. Several categories were dismissed and new were formatted and some were merged. During this process the codes were constantly compared with the original text. Codes were merged into final categories (Table 2) covering the full content of the interviews, and categories were further condensed into core categories and one final overarching category expressing the essence of the experiences.

\section{ETHICS}

Ethical approval was obtained from the Regional Ethics Committee, Lund Sweden (LU 667-02). Written and oral information were given including; the design of the study; the right to withdraw without giving a reason; and that they were guaranteed confidentiality. All participants gave written consent to participate. The study was performed according the guidelines of the Helsinki Declaration of ethics [15].

\section{RESULTS}

Four core categories were emerged to illuminate the meaning of the informants' experiences and to gain understanding. These were condensed further into one over-arching category-Mental health patients alter between positive and negative experiences but still the latter is overwhelming - expressing the essence of the study. Mental health patients can not be considered a homogeneous group. Their experiences are dependent on the occasion, who they meet and what situation they are in. Despite the fact that many reported improvement the overwhelming message of the narratives was that they were still fragile individuals whose experiences were not taken into account by mental health professionals or by their social networks.

\subsection{Diverging Perceptions of Mental Illness Due to Various Acceptance and Knowledge}

The informants' experiences of public perceptions and attitudes regarding mental illness varied from having a positive to a negative feeling regarding acceptance and knowledge. Those informants who stated that acceptance and knowledge about mental illness among the public had increased also maintained that mental health problems have become more common recently, resulting in a greater acceptance. Contrary to these optimistic perceptions there were informants who were convinced that public knowledge and acceptance still were at a low level. They described public perceptions as being characterized by deeply rooted negative stereotypes. Some informants expressed feelings that people who did not know them often viewed them as less intelligent and incompetent. Facing such perceptions made them feel devalued and frustrated.

"We have so many individual problems, all of us, and when it comes to mental illness they bunch everything together and there's criminals and types like the one who murdered Anna Lind (Swedish foreign minister, author's comment) '. I feel that one is branded, well and truly."

Media such as internet, television, newspapers and movies were often cited as the main source of information about mental illness for the general public. The informants maintained that media were responsible for creating the image of mentally ill persons often appearing in police reports and in a context where violent acts occur. They were afraid that this might strengthen the general public's fear and call for a return to traditional institutional care. One informant stated:

There is probably a common fear $\cdots$ people project a great fear about the mentally ill $\cdots$ that a person with mental illness can commit a terrible, a horrible crime without any reason at all ${ }^{\prime}$ I can understand people being afraid of that.

Table 2. Example of the analytic interpretation process.

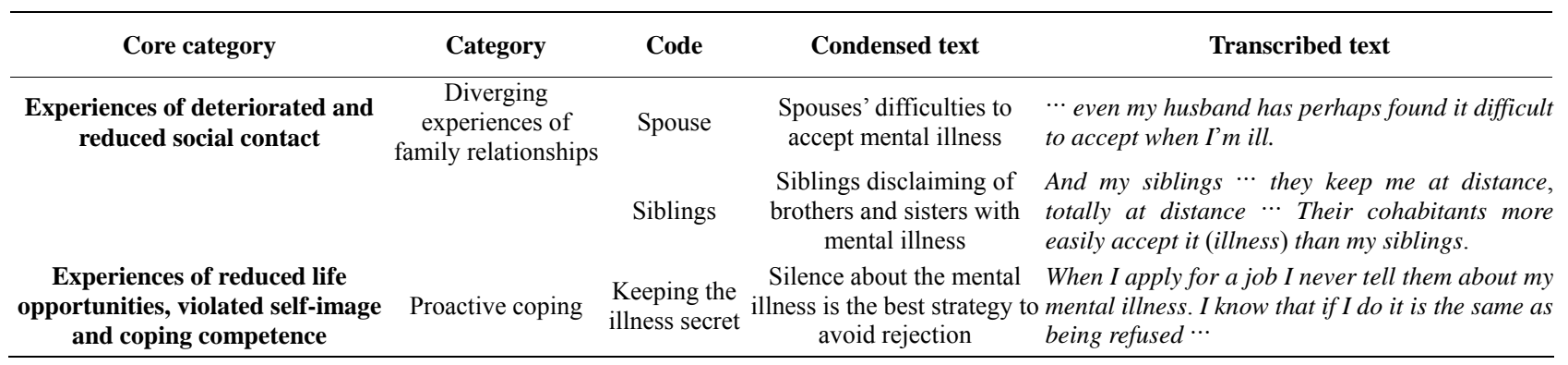




\subsection{Experiences of Deteriorated and Reduced Social Contact}

This core category refers to the informants' experiences in the context of social relationships. Mostly the diagnosis had resulted in deteriorated or reduced social contacts. This category is built up by two categories entitled; Experiences of social relationships in general and Diverging experiences of family relationships.

\subsubsection{Experiences of Social Relationships in General}

Feelings of not being understood by those who were not affected by mental illness were common among the informants. They described difficulties in dealing with new acquaintances, since they did not know how these would react when being told about their problems. They described the fear of losing new friends. One informant described it as: "If this person finds out that I have a mental illness, what will happen then? Will that person disappear, will that person stay? Those are the thoughts that come almost automatically"

Some experiences were socially dismissing, leaving the informants with a sense of being overprotected or viewed as infantile.

"Either they couldn't manage to be with me or they would be kind and pleasant towards me as though I was a child. This was very degrading in some way."

The feelings of being socially insecure or worried about people around them was often felt in new situations but these feelings were reduced when they met friends in the same situation as themselves. The feeling of sharing the same destiny and facing the same problems created a feeling of solidarity with others. However, the informants sometimes experienced ambivalence towards these relationships due to their situation of being trapped in old social structures not promoting their development.

"....you can't be together with people who are mentally ill all the time. Life does not just entail finding someone to be with who has the same illness as oneself."

\subsubsection{Diverging Experiences of Family Relationships}

The interactions in the families varied greatly. Basically the relatives either behaved in a supportive or avoiding way. Experiences of being met with silence or by avoidance and reluctance to talk directly about aspects of mental illness were common.

“Mental illness doesn't exist in my family. They've met me with silence because one isn't supposed to be mentally ill."

Those informants, who at the time of the onset of their illness had already started a family, spoke of a more or less involuntary abdication from the role of being a par- ent when they had become ill. A great fear of relapse into illness affected their families a long time after their recoveries. The feeling that their family had lost confidence in them was reinforced by their relatives' worry and overly protective manner. They described that their need to talk to relatives could sometimes be hampered because the latter were felt uncomfortable when they spoke about the psychiatric diagnosis. The feeling of suffering from an illness that was seen as being a burden on the family's reputation and of falling short of relatives' expectations were hard to bear.

"It was really demoralizing for such a family, upper class and all that. It just didn't fit in with their reality. It was a disgrace for them."

Some of the informants spoke about their families as gradually learning to accept that their mental illness, while others talked of their families disclaiming them. When their relatives appealed to them to "just pull you together" or "be reasonable" they felt it was frustrating. They spooked about how the families had supported them and been partners in the struggle to cope with and gain control over the illness. One informant said: "My family is very strong. They're always there and let me come home when I'm not well. Then it's easier to get back up from my down periods". However, those informants who have been supported felt that their relatives should have received more support from the authorities.

\subsection{Experiences of Reduced Life Opportunities, Violated Self-Image and Coping Competence}

This core category refers to the informants' experiences of daily living as well as plans of the future, and was built of three categories: Reductions of life opportunities; Influences on self-image, self-esteem and proactive coping.

\subsubsection{Reduction in Life Opportunities}

The prejudices about mental illness and the symptoms, such as problems with mentally focusing, being sensitive for stress, tiredness and frequent admissions to hospital had caused them to give up or change their plans for the future. The informants stated that the psychiatric diagnosis had meant that they had lost many years. Hindrance of developing was associated with uncompleted study program, loss of jobs and friends who had abandoned them.

"I'm standing on exactly the same spot as I did seven years ago. Sometimes I can sleep for two or three days at a time, so you think, I can sleep for the rest of my life. I want more quality in my life."

Their expectation of their future life was poor with limited social networks, sometimes only to staff mem- 
bers. Workmates made sarcastic remarks or underestimated their abilities. They had also experienced that they had been forced to resign from jobs when employers found out that the informants suffered from mental illness.

\subsubsection{Influences on Self-Image and Self-Esteem}

The reaction to their psychiatric diagnoses, especially the period after having received their diagnoses, was dominated by thoughts of accusing themselves, feeling shame and lower self-esteem. They felt they did not live up to how they were expected to be. The comparison with other people caused feelings of inferiority and loss of their own dignity.

"Everything has to be as new as possible, as expensive as possible and glamorous in terms of life and everything $\cdots$ well if you're mentally ill and tried to take your own life then you're far away from this image of how life should be."

The desire to live a normal life like the other people in the community was huge. The feeling of not having the same possibilities as others' was difficult to accept. Some reported several years of self-stigmatizing and feelings of guilt and they felt in some way responsible themselves for having a psychiatric diagnosis.

"I had my own prejudices also. So it was very difficult to accept that I should have an illness ${ }^{\cdots}$ I was stigmatizing myself for many years, made myself feel small. I'm not worth anything '. I didn't have feelings of guilt because I had done something wrong, but because there was something wrong with me..."

\subsubsection{Proactive Coping}

Experiences varied from basically keeping their illness as a complete secret to being able to show a greater openness about it. Informants also conveyed an awareness of the tendency to be restrained about talking about their illness originating both from earlier experiences and their own prejudices. A woman, who for most of her life had chosen not to speak of her illness, described her childhood as: "The community where I grew up '* it was a very destructive community, as small villages can be where everyone is moulded in the same form. I know that it was very difficult for those who had some sort of deviating behaviour. They had to leave..."

It was important to be able to choose who and when they wished to talk about things associated with their psychiatric diagnoses. Even those who had been very restrained sometimes had a need to talk however; they often chose situations where they could be anonymous.

The informants who had experience of stigmatizing behaviour from people around them declared that they had developed an ability to assess people's attitudes to- wards them.

This watchfulness for the attitudes of those around them led sometimes to a feeling of being constantly tense and a worry that was so strong that they sometimes feared it would cause some physical illness. The informants who had some form of employment stated that if it were known that they suffered from mental illness they could risk losing their job.

"I become physically ill through having the pressure on me, of not being allowed to be mentally ill."

The aversion to revealing symptoms to people around them was an important incentive for them to cope with and gain control over their illness. Those who had spent a lot of time trying to understand their illness felt that it was important to be able to distinguish between their own person and the illness they had. This insight had been a first step on the way to stopping self-stigmatizing.

\subsection{Ambivalent Contacts with the Mental Health Services}

In general the informants felt that the attitudes and approach of staff had changed for the better during the 1990s. They described mental health service staff as "more agreeable", "more friendly" and "easier to deal with" than they had previously been. However, they stated that being admitted to a psychiatric ward had been a terrifying experience, particularly on the first occasion. Feelings of shame, confusion, failure and worry about what was going to happen to them were common. Staff members' involvement created feelings of security in the patients, while shortcomings strengthened feelings of fear and confusion.

I didn't know from the beginning what they were going to do with me. I became even more scared; when I felt bad ${ }^{\cdots}$ I spent three days in the intensive care unit $\cdots$ And that was good, actually. Good people who worked there .. They understood when you weren't feeling well."

Lack of information on their diagnosis was something that also affected the informants. They spoke of having had fantasies and had wondered about what their diagnosis actually meant to them. Not knowing about the diagnosis had meant that they had been prevented from understanding their own reactions and behaviour.

The informants also criticised the doctors for giving different and new diagnoses on the different occasions they had been admitted. One informant wondered: "How can people who are educated in the same field give so different, so many different, diagnoses."

They also stated that they themselves, as well as many others with mental illness, did not receive the help they needed and wondered why it was so difficult to get access to mental health services. Why had one to be so "extremely ill" in order to be admitted? The informants 
spoke of their wish for the development of new services, where they could meet with others in the same situation and gain access to professional staff. They were also critical of staff members who did not listen to what they had to say or did not pay attention to their individual needs. Their experience was of being offered a standard treatment, which generally consisted of which medication to be prescribed: "They only see a condition, a symptom and give medication straight away."

Those who had received counselling therapy spoke very positively of this. They thought that they had been helped and that "without the therapy I wouldn't have been as well as I am today". But the informants voiced an opinion that they had often not recognized the descriptions of themselves as reported in the documents when they had been subjected to compulsory care. This had created feelings of confusion and distrust towards the doctors. They thought that compulsory care could have been avoided if the staff had endeavoured to motivate them to receive care voluntarily. One informant said;

"It can be a shocking experience if there's violence and the police are involved. Why not send a doctor who can take a little at a time. Why do the police have to be involved at all? One hasn't committed a crime."

\section{DISCUSSION}

The aim of the present study was to gain an understanding of experiences of mental health patients related to their mental illness. Trustworthiness of the analysis $[16,17]$ was supported through analyses by three of the authors (BL, PL, and BS) and further strengthened by the fact that the first author conducted all of the interviews. Further follow up questions were used to improve trustworthiness. The interviews varied in richness, and included a wide range of experiences. The non-directive interview style, with the use of one opening question, offered a possibility for the informants to talk about their experiences without restricting themselves. Thus it is hoped that the complexity of the informants' experiences was expressed and the credibility of the findings enhanced.

Findings showed that the mental health patients' experiences varied a lot in many aspects related to affirmative and discriminative relationships in many different social constellations as family, friends, work settings and care situations. However, despite of some affirmative experiences the overwhelming narratives disclosed an exposed situation? Their telling during the interviews strongly emphasized that society, care and closer social networks still did not account their experiences enough to change the interactions to the better. Maybe the general perception is that the main problem is within the patient.
Findings from the present study also mirror those of previous studies using questionnaires investigating perceptions of stigma and strengthen the conception that stigma is a reality for patients with mental illness. There is strong evidence that patients with a psychiatric diagnosis expect or anticipate discrimination, whether or not this actually takes place $[18,19]$.

The personal distance in proximate relationships has been reported previously $[9,20]$ but the intensity of experiences reported here was very strong and was unanimously expressed. Thornicroft [21] suggests that the use of stigma is limited and focuses on individual aspects of discrimination, rather than identifying social causes leading to social exclusion. The focus should rather be on the power to discriminate [22], not the results of discriminative processes. Proactive coping expressed an awareness of the mutual aspects of the discriminative process in the sense that informants mainly tried to cope with situations in which they expected themselves to feel uncomfortable or devaluated by avoiding them. Still, this was an individualistic style of coping since they experienced little or no power to affect their environment.

Findings by Angermeyer et al. and Ucok et al., [19,23] have indicated that patients anticipate stigmatization more frequently than they actually experience stigmatization, particularly regarding access to work. The latter finding is in agreement with the results from the present study. The development and growth of self-image is a relational activity involving many social aspects of interpersonal expectations. Reduced life opportunities are a result of a social exchange process involving at least two parts, and often many more. To increase quality of life is not only a passive position of receiving qualities but an active acceptance of the qualities available to develop a positive spiral of higher and higher levels of life satisfaction. The anticipation of stigmatization can be a hindrance in the process of taking a proactive attitude to possibilities at hand in the life situation. However, if mental health patients are denied inclusion into social networks, the individual is highly discriminated in the task of gaining inclusion.

Our results indicated that attempts to hide or conceal a history of psychiatric treatment sometimes resulted in stress and isolation. These findings are in accordance with Goffman [4] who believed that managing a discreditable identity that is not apparent to others can be a powerful source of anxiety. Smart and Wegner and Lv et al. [24,25] found that people who conceal their stigmas reported a continuing preoccupation with secrecy. This preoccupation with secrecy has been described as a "private hell" [26]. Most informants in the present study chose to selectively share information about their illness to avoid exposing themselves to stereotypes and prejudices held by the public. 
Schulze [27] highlights the experience expressed by the users that psychiatrists need to acknowledge that they sometimes focus too much on careless use of diagnostic labels instead on focusing on recovery, collaboration in treatment and promotion of community-based services. However, the service users in this study expressed clearly a need of more agreement between the psychiatrist's diagnosis and the view of the person concerned to avoid the feeling of being reduced as a person.

Findings also showed that meeting others in a similar situation increased understanding of their own situation and decreased social isolation. Informants developed a feeling of self-worth and reduced feelings of loneliness. Many emphasized that this realization had helped them to recover from stigma. However, the results also showed that the relationships with other users sometimes were perceived as too focused on issues related to their illness. Although issues of friendship may be important for users of mental health services, this is an area which has attracted very little interest among researchers [23]. The research up to now in this field has revealed that people with more severe forms of mental illness have more limited social networks than others and have relatively more family members than friends in their social net $[28,29]$.

Our data on the experiences of mental health patients correspond with findings in other studies [30,31] and illustrate that consumer groups want more participation and collaboration in planning their own care and improvement in routines of post-discharge follow-up. There is a broad common sense among mental health patients that every human being has an intrinsic value, but still the question can be raised if every human being has an equal life value? This question is very problematic in relation to the beginning and end of life, but it is relevant for many other situations and groups of human beings, such as people with a psychiatric functional disability. The informants' experiences give a unanimous answer to the question. If they are treated and reaffirmed as human beings, as persons, we are better able to handle hassles in everyday situations. The better the mental health patient is reaffirmed by care providers, family, employers and friends the more they feel themselves to be included in social relationships and societal activities. They also maintained that it was easier for them to feel self-confidence and to look upon themselves as persons with an intrinsic value independent of their mental health history. On the contrary, almost all informants reported experiences undermining their self-confidence leading to hopelessness, alienation, and social withdrawal. These experiences over time undermined their capability to look upon themselves as valuable and capable persons with an intrinsic human value. It is problematic that discriminative experiences were also experienced as having been betrayed by mental health professionals $[32,33]$. Service users are sometimes not capable of speaking for themselves or are not listened to. This study confirms Bolton's [32] ethical reasoning.

\section{CONCLUSION}

In conclusion, the findings from the present study can contribute to the understanding of mental health patients' situation and to improve the professional contact with them. Further research is needed to confirm the findings of the present study.

\section{CLINICAL IMPLICATIONS}

The results may help nurses and other professionals in many contexts to understand the importance of mental health patients' earlier experiences in caring situations. This knowledge may strengthen the implications of patient centred care essential for the outcome of the care.

\section{ACKNOWLEDGEMENTS}

The authors wish to thank the participants' who participated in the study.

\section{REFERENCES}

[1] Bjorkman, T., Angelman, T. and Jonsson, M. (2008) Attitudes towards people with mental illness: A cross-sectional study among nursing staff in psychiatric and somatic care. Scandinavian Journal of Caring Sciences, 22, 170-177.

http://dx.doi.org/10.1111/j.1471-6712.2007.00509.x

[2] Leff, J. and Warner, R. (2006) Social inclusion of people with mental illness. NY University Press, Cambridge. http://dx.doi.org/10.1017/CBO9780511543937

[3] Hansson, L. and Bjorkman, T. (2005) Empowerment in people with a mental illness: Reliability and validity of the Swedish version of an empowerment scale. Scandinavian Journal of Caring Science, 19, 32-38. http://dx.doi.org/10.1111/j.1471-6712.2004.00310.x

[4] Goffman, E. (1986) Stigma: Notes on the management of spoiled identity. Touchstone Edition, New York.

[5] Link, B.G. and Phelan, J.C. (2001) Conceptualizing stigma. Annual Review Sociology, 27, 363-385. http://dx.doi.org/10.1146/annurev.soc.27.1.363

[6] Link, B.G., Yang, L.H., Phelan, J.C. and Collins, P.Y. (2004) Measuring mental illness stigma. Schizophrenia Bulletin, 30, 511-541. http://dx.doi.org/10.1093/oxfordjournals.schbul.a007098

[7] Schulze, B. and Angermeyer, M.C. (2003) Subjective experiences of stigma. A focus group study of schizophrenic patients, their relatives and mental health professsionals. Social Science \& Medicine, 56, 299-312.

[8] Gonzalez-Torres, M.A., Oraa, R., Aristegui, M., Fernandez-Rivas, A. and Guimon, J. (2007) Stigma and discrimination towards people with schizophrenia and their 
family members. A qualitative study with focus groups. Social Psychiatry and Psychiatric Epidemiology, 42, 1423. http://dx.doi.org/10.1007/s00127-006-0126-3

[9] Lakeman, R., McGowan, P., MacGabhann, L., Parkinson, M., Redmond, M., Sibitz, I., et al. (2012) A qualitative study exploring experiences of discrimination associated with mental-health problems in Ireland. Epidemiology and Psychiatric Sciences, 21, 271-279. http://dx.doi.org/10.1017/S2045796012000017

[10] Halding, A.G., Heggdal, K. andWahl, A. (2011) Experiences of self-blame and stigmatisation for self-infliction among individuals living with COPD. Scandinavian Journal of Caring Science, 25, 100-107. http://dx.doi.org/10.1111/j.1471-6712.2010.00796.x

[11] Buizza, C., Schulze, B., Bertocchi, E., Rossi, G., Ghilardi, A. and Pioli, R. (2007) The stigma of schizophrenia from patients' and relatives' view: A pilot study in an Italian rehabilitation residential care unit. Clinical Practice and Epidemiology in Mental Health, 3, 23. http://dx.doi.org/10.1186/1745-0179-3-23

[12] Lundberg, B., Hansson, L., Wentz, E. and Bjorkman, T. (2007) Sociodemographic and clinical factors related to devaluation/discrimination and rejection experiences among users of mental health services. Social Psychiatry and Psychiatric Epidemiology, 42, 295-300. http://dx.doi.org/10.1007/s00127-007-0160-9

[13] Burnard, P. (1991) A method of analysing interview transcripts in qualitative research. Nurse Education Today, 11, 461-466. http://dx.doi.org/10.1016/0260-6917(91)90009-Y

[14] Burnard, P. (1996) Teaching the analysis of textual data: An experiential approach. Nurse Education Today, 16, 278-281. http://dx.doi.org/10.1016/S0260-6917(96)80115-8

[15] Helsinki Declaration. World Medical Association (2008) Ethical principles for Medical Research involving Human Subjects.

http://www.wma.net/en/30publications/10policies/b3/inde $\underline{x . h t m l}$

[16] Denzin, N.K. and Lincoln, Y.S. (2005) The sage handbook of qualitative research. 3rd Edition, Sage Publications Ltd., London.

[17] Lincoln, Y.S. and Guba, E.G. (1985) Naturalistic inquiry. Sage Publication, Thousand Oaks.

[18] Thornicroft, G., Brohan, E., Rose, D., Sartorius, N. and Leese, M. (2009) Global pattern of experienced and anticipated discrimination against people with schizophrenia: A cross-sectional survey. Lancet, 373, 408-415.

[19] Ucok, A., Brohan, E., Rose, D., Sartorius, N., Leese, M., Yoon, C.K., et al. (2012) Anticipated discrimination among people with schizophrenia. Acta Psychiatrica Scandinavica, 125, 77-83.
[20] Larson, J.E. and Corrigan, P. (2008) The stigma of families with mental illness. Academic Psychiatry, 32, 87-91. http://dx.doi.org/10.1176/appi.ap.32.2.87

[21] Thornicroft, G. (2006) Actions speak louder-Tackling discrimination against people with mental illness. Mental Health Foundation, London.

[22] Sayce, L. (2003) Beyond good intentions. Making antidiscrimination strategies work. Disability \& Society, 18, 625-642. http://dx.doi.org/10.1080/0968759032000097852

[23] Angermeyer, M.C., Beck, M., Dietrich, S. and Holzinger, A. (2004) The stigma of mental illness: Patients' anticipations and experiences. International Journal of Social Psychiatry, 50, 153-162. http://dx.doi.org/10.1177/0020764004043115

[24] Smart, L. and Wegner, D.M. (1999) Covering up what can't be seen: Concealable stigma and mental control. Journal of Personality and Social Psychology, 77, 474486. http://dx.doi.org/10.1037/0022-3514.77.3.474

[25] Lv, Y., Wolf, A. and Wang, X. (2012) Experienced stigma and self-stigma in Chinese patients with schizophrenia. General Hospital Psychiatry.

[26] Smart, L. and Wegner, D.M. (2000) The hidden costs of hidden stigma. In: Heatherton, T.F., Kleck, R.E., Hebl, M.R. and Hull, J.G., Eds., The Social Psychology of Stigma, Guilford, New York, 220-242.

[27] Schulze, B. (2007) Stigma and mental health professionals: A review of the evidence on an intricate relationship. International Review of Psychiatry, 19, 137-55. http://dx.doi.org/10.1080/09540260701278929

[28] Buchanan, J. (1995) Social support and schizophrenia: A review of the literature. Archives of Psychiatric Nursing, 9, 68-76. http://dx.doi.org/10.1016/S0883-9417(95)80003-4

[29] Thornicroft, G., Rose, D., Huxley, P., Dale, G. and Wykes, T. (2002) What are the research priorities of mental health service users? Journal of Mental Health, 26, 123-131.

[30] Beels, C.C., Gutwirth, L., Berkeley, J. and Struening, E. (1984) Measurements of social support in schizophrenia. Schizophrenia Bulletin, 10, 399-411. http://dx.doi.org/10.1093/schbul/10.3.399

[31] Chamberlain, J. (2005) User/consumer involvement in mental health service delivery. Epidemiologica e Psichiatria Sociale, 14, 10-14. http://dx.doi.org/10.1017/S1121189X00001871

[32] Bolton, J. (2003) Code of ethics for social work: BASW.

[33] Allen, M.H., Carpenter, D., Sheets, J.L., Miccio, S. and Ross, R. (2003) What do consumers say they want and need during a psychiatric emergency? Journal of Psychiatric Practice, 9, 39-58. 